\title{
DIOS, LÓGOS Y FUEGO EN HERÁCLITO ${ }^{1}$
}

\author{
Sebastián Aguilera Quiroz \\ Pontificia Universidad Católica de Valparaíso. Chile
}

\begin{abstract}
Resumen: El pensamiento filosófico de Heráclito posee innumerables aristas desde las que puede ser abordado. Pero es innegable el peso que tienen los conceptos de theós, lógos y $p \hat{y} r$ dentro de su "sistema". Este artículo propone la reunión de estas tres nociones tanto como su articulación intrínseca en lo que podría llamarse "metafísica heraclítea", es decir, se propone desentrañar la unidad del pensamiento fragmentario de Heráclito a la luz de la interconexión de las tres manifestaciones de dicha unidad.
\end{abstract}

Palabras Clave: Dios - Fuego - Lógos - Heráclito - Unidad

\section{GOD, LOGOS AND FIRE IN HERÁCLITUS}

Abstract: The philosophical thought of Heraclitus has countless edges from which can be approached. But it is undeniable the importance of the concepts of theós, lógos and $p \hat{y} r$ within their "system". This paper aims the meeting of these three notions as much as its intrinsic articulation of what might be called "heraclitean metaphysics", that is, it is proposed to unravel the unity of fragmentary thought of Heraclitus in the scope of the interconnection of the three manifestations of the unit.

Keywords: God - Fire - Lógos - Heraclitus - Unity

Recibido: 22.01.14 - Aceptado: 18.04.14

Correspondencia: SEBASTIÁN R. Aguilera Quiroz. sebastian.aguilera.q@gmail.com Licenciado en Filosofía y Educación, Profesor de Filosofía. Dr. @ en Filosofía por la Pontificia Universidad Católica de Valparaíso. Ayudante de Cátedra Griego I en PUCV. Miembro fundador del Centro de Estudios del Mundo Antiguo (CEMA), Instituto de Filosofía, PUCV. Miembro de Asociación Chilena de Filosofía (ACHIF) Becario CONICYT. Dirección: Avda. El Bosque 1290, Sausalito, Valparaíso.

${ }^{1}$ El presente trabajo fue leído en el III Congreso Nacional de Filosofía, organizado por la Achif (Asociación Chilena de Filosofía), Noviembre de 2013, Valparaíso, y se enmarca dentro de la investigación de Doctorado en Filosofía que realizo en la PUCV, bajo la dirección de Dr. Héctor García Cataldo. Se presenta aquí con las debidas correcciones y ampliaciones de contenido y forma. 


\section{Preliminares}

C6 odos los distintos temas que forman el conjunto de la filosofía de Heráclito están recíprocamente contenidos unos en otros" ${ }^{2}$, escribió con total acierto Enrique Hülsz, el editor de los Nuevos Ensayos sobre Heráclito. Actas del $2^{\circ}$ Symposium Heracliteum ${ }^{3}$, celebrado en 2006 en México, en el que participaron grandes eminencias en los estudios presocráticos y específicamente heraclíteos actuales, como son Serge Mouraviev, Livio Rossetti, David Sider, Daniel Graham, el mismo Enrique Hülsz, etcétera. Sus palabras dan el punto de partida desde el que comenzaremos a mostrar cómo esto es efectivamente cierto y desde dónde se articula este estudio. Por ello, intentaremos abordar el pensamiento de Heráclito, primero, basándonos en que existe una coherencia interna en su pensar, es decir, en que su filosofía es unitaria ${ }^{4}$, y segundo, analizando las relaciones existentes entre las nociones de $\theta \varepsilon o ́ \varsigma, \lambda o ́ \gamma o \zeta$ y $\pi \tilde{u} \rho$ dentro de esta su filosofía, como fundamento de la unidad de la misma. De este modo, asumimos de entrada que se puede hablar de una

\footnotetext{
${ }^{2}$ E. HüLsz 2001: 67.
}

${ }^{3}$ E. HüLsz 2009. Cf. también F. Barruecos 2012.

${ }^{4}$ W. Jaeger 1962²: 179-180: "Frente a los filósofos primitivos, aparece Heráclito como la primera antropología filosófica. Su filosofía del hombre es, por decirlo así, el más interior de los círculos concéntricos, mediante los cuales es posible representar su filosofía. Rodean al círculo antropológico el cosmológico y el teológico. Sin embargo, no es posible separar estos círculos. En modo alguno es posible concebir el antropológico independientemente del cosmológico y del teológico. El hombre de Heráclito es una parte del cosmos. Como tal se haya sometido a las leyes del cosmos como el resto de sus partes". Estos esbozos de unidad que plantea Jaeger aquí y en otros pasajes nos muestran algo que consideramos esencial para la interpretación de Heráclito, que es pensar su filosofía como la reunión de múltiples ámbitos en una unidad coherente, que Heráclito evidencia en su propia visión de la naturaleza. A la lectura de los fragmentos no puede escaparse la conclusión de una unidad que los atraviesa, por eso nunca serán vanas las tentativas de reconstrucción del texto completo del filósofo, desde Schuster hasta Mouraviev, que no hacen sino intentar reconstruir una unidad que se aprecia a todas luces. Se han hecho muchos avances desde Schuster (1872) a Mouraviev (2011), pero, si bien es cierto que el cien por cien de fidelidad y certeza es algo improbable, sus intentos nos acercan a comprensiones cada vez mayores del escrito heraclíteo y profundizan en su sabiduría abismal. 
"filosofía de Heráclito de éfeso" y que además, ella "se juega pricipalmente en las interacciones de estas tres nociones".

A simple vista, los fragmentos muestran señas de una cierta referencia a las mismas cosas, reiteraciones, interpolaciones y analogías que nos hacen pensar que una o más ideas apuntan a lo mismo. Esto es verdad. Pero hay que dejar que se muestre para lograr comprenderlo realmente. La idea del $\theta \varepsilon$ ć $\varsigma$ es complicada en el sentido en que nos obliga, al estudiar a Heráclito, a deshacernos de nuestras representaciones usuales, inconscientes, naturalizadas de lo que la traducción de la palabra $\theta \varepsilon o ́ \varsigma$, más no ella misma, quiere decir, pues correríamos el riesgo de sesgar nuestra interpretación. Consideremos solamente que $\theta \varepsilon$ ó $\varsigma$ es una palabra de incierta etimología ${ }^{5}$. Seguramente proviene de la raíz $* d h \bar{e} s$, de donde también el latín fas, con matices, que apunta a algo divino, quizá algun objeto religioso que seguramente tiene que ver con el ámbito de lo sagrado, por un lado, y por otro, esta raíz se relaciona con el hablar, pues también se entrecruza, posiblemente, con la raíz de fari, "hablar", *for ${ }^{6}$. De modo que $\theta \varepsilon$ có incluye, al menos en tiempos de Heráclito, una referencia a lo divino, a lo sagrado, y a la comunicación o manifestación de su naturaleza, no más ${ }^{7}$. Así, debemos olvidar nuestra representación del Dios cristiano (a pesar que no entraremos a discutir aquí si lo divino en Heráclito apuntaría o no a esa imagen) para poder sumergirnos en el mundo politeísta, pagano, de la Grecia antigua y que a la vez es un sumergirse, en época arcaica y en Heráclito, en una suerte de panteísmo monista o monismo panteísta, en expresión de Wilhelm Capelle. Así de complejo es, a primera vista, el tema de lo divino en Heráclito. La noción de $\lambda$ ó $\gamma o \zeta$, por su parte, se presta más fácilmente a la comprensión, especialmente desde la filosofía, pues tiene que ver con buena parte del hacer filosófico, en dos sentidos, que se precisarán en lo que sigue. Uno de ellos tiene que ver con que $\lambda$ ó $o \varsigma$ en Heráclito apunta a un principio metafísico que rige el devenir del universo y por ello, podría pensarse como ley del universo. Esta idea, a partir de los fragmentos, arrastraría consigo también al hombre, pues Heráclito atribuye a la mismísima alma un $\lambda o ́ \gamma o \varsigma$, de imprecisa definición ${ }^{8}$. Otra arista del $\lambda o ́ \gamma o \varsigma$, y que no deja de ser interesante, es

${ }^{5}$ Cf. P. Chantraine 1968: 430 (s. v. $\left.\theta \varepsilon o ́ c\right)$.

${ }^{6}$ Cf. E. Benveniste 1983: 317 ss.

${ }^{7}$ Especialmente contra las visiones que intentan ver en el $\theta \varepsilon$ có Porque si bien comparten cualidades semejantes, no existe trabajo serio que vincule el pensamiento hebraico con el pensamiento de Heráclito. El único trabajo, que conocemos, que más o menos transita ese camino es el de W. Kranz 1949.

${ }^{8}$ Cf. A. Cappelletti 1974; W. Cappelle 1981; A. Kostas 1962; W. Jaeger 1952, 1962 ;2 W. Guthrie 1991; G. Colli 2010, M. Marcovich 2001²; H. FränKel $2004^{2}$. 
la relación que tiene también con la filosofía, pero en el ámbito del discurso, de la construcción teórica, de la razón y argumento de que se vale el pensador para expresarse?.

Finalmente, el $\pi \tilde{o} \rho$ se presenta como el concepto que menos referencias claras tiene, es decir, referencias que nos den luces precisas acerca del lugar que cuparía en la filosofía heraclítica. Pero no es imposible, a partir de las veces en las que se recurre a él en contextos precisos, que apuntan ya a una ya otra de las dos nociones anteriores, caracterizarlo con mediana presición. Proponemos partir del análisis de esta última noción para ir descubriendo ahí las demás y llegar a la que creemos principal en esta tesis de la unidad de la filosofía de Heráclito.

\section{1. $\pi \tilde{\mathrm{\nu} \rho}$}

Si pensamos este concepto en su sentido material, nos podemos encontrar con alusiones bastante claras en varios fragmentos, veamos, para partir, el Fr. B 31 ${ }^{10}$ : "Transformaciones del fuego: primero el mar, luego, del mar la mitad tierra y la mitad vapor inflamado (prestér)" ${ }^{11}$. Dicho sea de paso, Clemente, quien da la

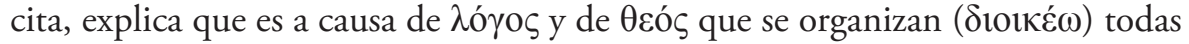

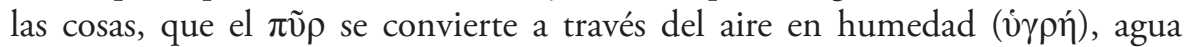
que actúa como semilla de la ordenación del mundo, a la que Heráclito llama 'mar'12. Esto significa que en B 31 el fuego se entiende física o materialmente, y podríamos hablar de un proceso cosmoglógico o cosmogónico en el que el fuego, quizá movido por $\lambda o ́ \gamma o \varsigma$ y $\theta \varepsilon o ́ \varsigma$-como sugiere Clemente-, se transforma en todas las cosas. Tal y como refiere el Fr. 90: "Del fuego son cambio todas las cosas

${ }^{9}$ En esta línea están, por ejemplo, M. Conche 1986; CH. Kahn 1979 y M. García Quintela 1992.

${ }^{10}$ Utilizaremos en general la traducción de Mondolfo, que se ajusta bien al texto de Diels-Kranz y, cuando se estime, la traducción en español de Marcovich en su Editio Minor de Heráclito. Cf. R. Mondolfo 2007, M. Marcovich 2001², 1968. Seguimos, por lo demás, la canónica numeración y el texto griego de los Vorsokratiker de H. Diels y W. Kranz, sin desmedro de las numeraciones que se le han dado al texto a partir de ahí, como la del mismo Marcovich o la más reciente y que es ya una edición indispensable para el estudioso, de Serge Mouraviev.

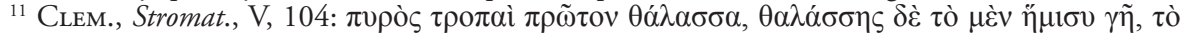

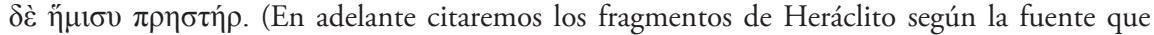
los transmite, por tanto, las abreviaturas de las obras de dichas fuentes se encuentran en la Bibliografía).

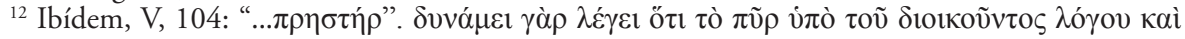

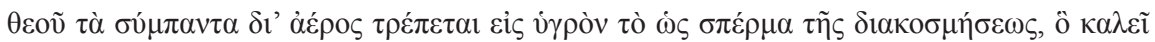
$\theta \alpha \dot{\lambda} \alpha \sigma \sigma \alpha \nu \ldots$ 
$y$ el fuego es cambio de todas, así como del oro [son cambio] las mercancías y de las mercancías el oro" 13 .

Estas últimas palabras abrazan casi toda caracterización del fuego en su sentido material, pero la coronación de esta idea la encontramos en el Fr. B 30: "Este cosmos, uno mismo para todos los seres, no lo hizo ninguno de los dioses ni de los hombres, sino que siempre ha sido, es y será fuego eternamente viviente, que se enciende según medidas y se apaga según medidas" 14 . Aquí Heráclito identifica el fuego, elevándolo a la categoría de principio universal constitutivo de todo, con el mundo, eternizando, además, su esencia. Lo que ya nos pone en camino para pensar el fuego ya no puramente en su sentido material, sino que nos abre el camino para pensar al fuego en su relación con la esencia divina del mundo, esto es, con el $\theta \varepsilon o ́ c$. Aquí la tradición (Clemente) ha puesto el fragmento B 31 después del B 30, inmediatamente después, pero creemos que para entender mejor el camino que va desde el fuego, en tanto material, al fuego cósmico de B 30 , es necesario anteponer el 31 al 30 e ir de lo particular a lo general.

Para comprender mejor cómo va adquiriendo el $\pi \tilde{v} \rho$ connotaciones cada vez más abstractas, hay que echar mano de dos cosas: primero, de la doble eternización de este principio en B 30 y segundo, del caracter "mesurado" de su

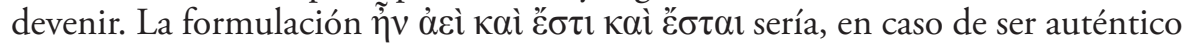
el fragmento (y no hay razones para dudarlo), la primera formulación de la eternidad de la que se tiene noticia : "era siempre, es y será", es decir, aquello que el кó $\sigma \mu \mathrm{o}$ es, es eterno. Primero, le atribuye una existencia eterna y luego le atribuye una nota que especifica más esa eternidad, esto es, además de que el fuego ( $\pi \tilde{\rho} \rho)$ sea eterno ("siempre ha sido, es y será"), es algo que siempre es viviente, es $\dot{\alpha} \varepsilon i ́ \zeta \omega o v$, siempreviviente ${ }^{17}$. Esto no es meramente una predicación,

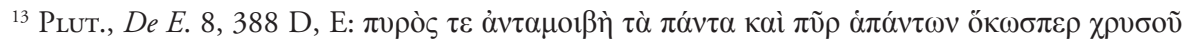

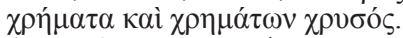

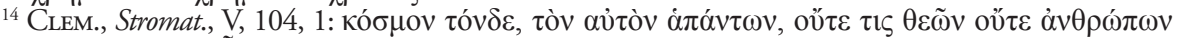

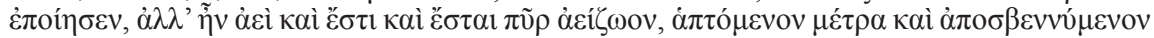
$\mu \varepsilon ́ \tau \rho \alpha$.

${ }^{15}$ Cf. G. S. Kirk 1962²: 325-326.

${ }^{16}$ R. Mondolfo 1934: 54 ss, 2007: 251. Cf. también, para la discusión G. S. KIRK 1962²: 310 ss.

${ }^{17}$ No podemos entrar aquí en la intrincada discusión acerca de si la fórmula ñर tiene sentido existencial (Ẽ̃v $\alpha$ l, un verbo enclítico, se acentúa cuando tiene valor existencial) o bien copulativo. Nuestra interpretación, en todo caso, no depende de la puntuación entre la

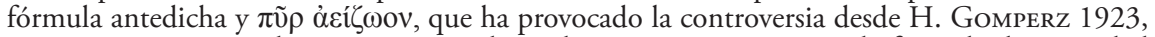
puesto que, en general y para no complicar el asunto, pensamos que la fórmula de eternidad que aparece en el fragmento no indica sino a la eternidad de кó $\sigma \mu \varsigma_{\zeta}$ como modalidad de la

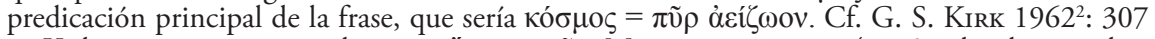
ss, Kirk pone un punto en alto entre ह̌ $\sigma \tau \alpha \iota$ y $\pi \tilde{v} \rho$; Mondolfo 2007: 249-253, donde se explica la controversia y sus razones, inclinándose a la no necesidad de puntuar en aquel lugar del

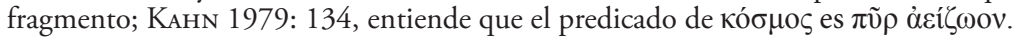


sino que nos dice algo respecto de cómo entiende Heráclito el mundo en general, esto es, como algo viviente, vivo.

Sin duda que esto está en concordancia con el sentir propio de su tiempo respecto de cómo concebir el mundo que nos rodea, la natura ${ }^{18}$. Esta vida del fuego

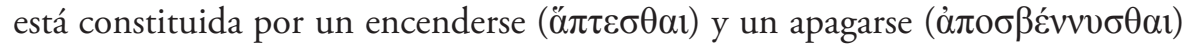
regulado por, entendemos, una justicia cósmica (presente, p. e., en el Fr. B 94: "El sol, pues, no traspasará sus medidas [ $\mu \varepsilon ́ \tau \rho \alpha]$; si no las Erinnias, ministras de

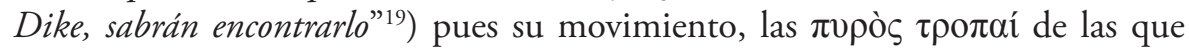
hablamos a propósito del Fr. B 31, que no son más que sus mutaciones, su

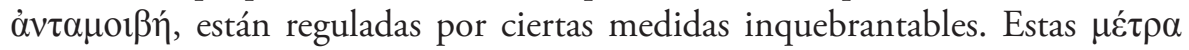
reguladoras mientan una necesidad en el acaecer del fuego, dando a conocer que su movimiento a parte de ser regulado, es necesario. Pero ahí donde nos hacemos la pregunta sobre qué es o a qué se refiere Heráclito con esto, es donde puede haber vislumbre de la divinidad, porque si tomamos conjuntamente el Fr. B 90, donde todas las cosas son mutaciones del fuego, y el Fr. B 30, donde el fuego es el cosmos eterno y vivo que se mueve de manera regulada, podemos equiparar esta asimilación: fuego $=$ todas las cosas $(\pi \tilde{\nu} \rho=\alpha \check{\alpha} \alpha \nu \tau \alpha)$, a lo divino, que también puede presentarse bajo la forma: divinidad = todas las cosas, como veremos a continuación.

\section{2. $\theta \varepsilon o ́ \varsigma$}

El tema del $\theta \varepsilon$ ó $\varsigma$ heraclíteo es sumamente complejo. Intentemos desgranarlo para ver las relaciones que contiene. Es destacable, en primer lugar, el estatus ontológico en el que Heráclito coloca al $\theta \varepsilon$ ó, , por lo que debemos revisar a grandes rasgos el conjunto de fragmentos B 82, B 83, B 78 y B 102. En el Fr. B 82: "El más bello de los monos es feo al compararlo con la especie de los hombres"20, Heráclito compara el mono con el hombre y coloca en una suerte de "escala de seres" al hombre por sobre el mono, pero en el Fr. B 83 ve al propio hombre

${ }^{18}$ Cf. S. Sambursky 2011: 66, 269, 301-2; W. Guthrie 1991; W. Jaeger 1982; O. Gigon 1980: 221; A. Cappelletti 1974: 19 ss.

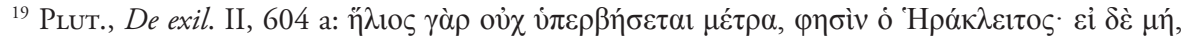

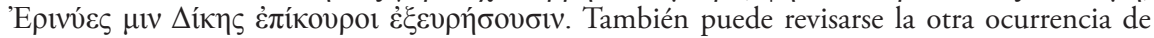

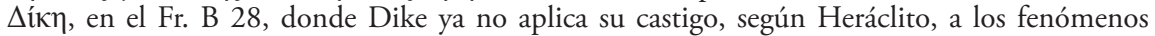

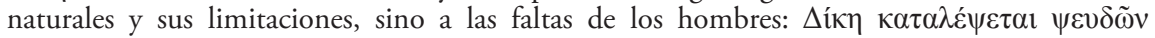

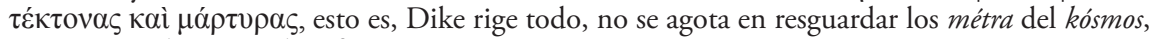
sino que también toca la esfera antrópica.

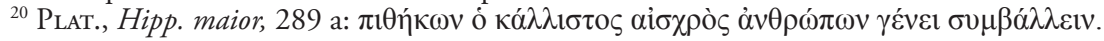


como un mono si es comparado con el $\theta \varepsilon$ co: "El más sabio de los hombres parecerá un mono en comparación con Dios, en sabiduria, hermosura y todo lo demás" ${ }^{2}$. Heráclito agrega, especificando por qué Dios es superor al hombre, que el conocimiento divino es el verdadero, no el humano, como queda recogido en Orígenes, quien nos transmitió el Fr. B 78: "[Heráclito a través de Celso]: «porque

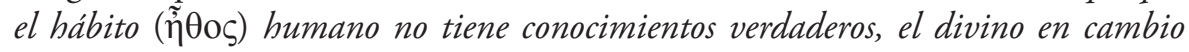
los tiene»' '22. Aquí es donde comienza la tipificación de la calidad del $\theta \varepsilon o ́ \varsigma$ de Heráclito. Para él, dios o lo divino, es superior en todo sentido al hombre, en todo sentido. Tanto es así que llega a enunciar una característica que sobrepasa todo el conocimiento humano, caracterizado por la división, por la parcelación de la realidad en compartimentos aislados a veces, someramente juntos, otras, y enuncia una característica de lo divino que se escapa a toda comprensión humana, puesto que va más allá de la misma, una intuición omniabarcante que tiene que ver, en nuestra interpretación, con la comprensión necesaria acerca de que, según Heráclito, el hombre debería tener -porque está facultado para ello- la comprensión respecto al contenido del $\lambda$ ó $\gamma$ o $\varsigma$, que no podemos tocar en esta presentación; se trata del Fr. B 102: "Para el Dios [ $\tau \tilde{\omega} \mathrm{\imath} \theta \varepsilon \tilde{\omega} 1$ ] todas las cosas son bellas y buenas y justas; los hombres, en cambio, consideran unas injustas y otras justas" 23 , es decir, las injusticias que nosotros consideramos más atroces, ayer y hoy, para la mirada divina, para su comprensión, son justas, bellas y buenas. Lo divino está más allá de lo humano de una manera tan absoluta que llega a ser difícil pensarlo dentro del pensamiento de Heráclito.

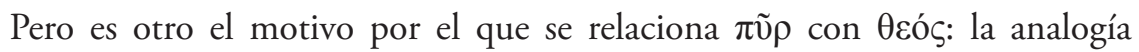
que presenta el famoso Fr. B 67, y que nos estaría dando noticias acerca de la relación posible que existe entre la noción de $\theta$ có $\zeta$ y la de $\pi \tilde{\rho} \rho$ en la filosofía heraclítea. Este fragmento está recogido por Hipólito de Roma en el libro IX de su Refutatio omnes haeresium, y se da una referencia a dios o lo divino que es, en palabras de Kirk: "una idea distinta de $\theta \varepsilon$ ć $̧$ de la que se deriva de otros fragmentos existentes. Los fragmentos 5, 24, 30 y 53 mencionan $\theta \varepsilon o i ́$ en un sentido puramente tradicional" 24 . He aquí el Fr. B 67: "Dios es: día y noche, invierno y verano, guerra y paz, saciedad y hambre; él toma diferentes formas, lo

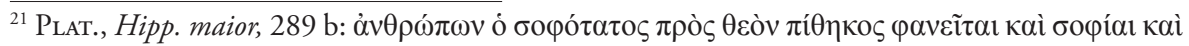

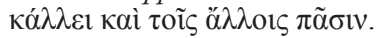

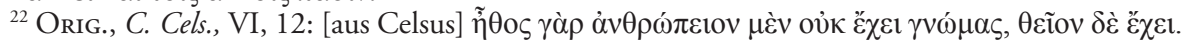

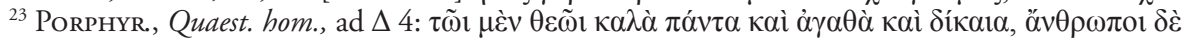

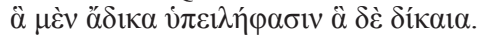

${ }^{24}$ G. S. KIRK 1962²: 188. 
mismo que el fuego, que al mezclarse con los sahumerios (inciensos) es llamado según el aroma de cada cual de estos" 25 . Se ve con claridad que $\theta \varepsilon$ có $\varsigma$ es pensado aquí, en

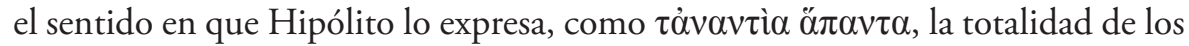
opuestos. Pero si nos preguntamos por qué se da el caso que dios sea "la totalidad de los opuestos", podemos pensar que los opuestos son el mismo mundo, la

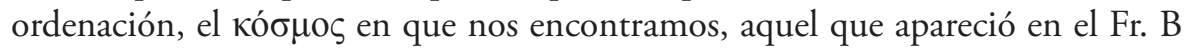
30 como identificado con el eterno fuego siemprevivo. Entonces, si kó $\sigma \mu \mathrm{o} \varsigma$ es un fuego siemprevivo y lo divino se transforma como el fuego, podemos relacionar el fuego con lo divino, al modo de dos nombres para representar la misma esencia: el cambio mesurado de dos polaridades en relación. Si esto es así, $\theta$ có $̧$ vendría a tener el mismo valor que $\pi \tilde{v} \rho$, sería un $\theta \varepsilon i ̃ o v ~ \pi \tilde{~} \rho$. En este sentido, podemos afirmar ya que $\theta \varepsilon o ́ \varsigma$ es equivalente, como veníamos diciendo a propósito de la relación fuego $=$ todas las cosas $(\pi \tilde{\nu} \rho=\ddot{\alpha} \pi \alpha \nu \tau \alpha)$, a todas las cosas, puesto que en la filosofía de Heráclito todo lo que hay no es más que los opuestos. La realidad está constituida por los opuestos y su lucha no es sino su devenir, su movimiento y su avance histórico. Por ello, en palabras de Gustavo Fernandez, autor del libro Heraclito: Naruraleza y Complejidad, donde pone sus esfuerzos en relacionar la filosofía heraclítea con el pensamiento de Edgar Morin: "Lo divino es la plena expresión de la unidad oculta del cosmos, la contemplación global del mismo (...) Lo divino radica en el ajuste creador e intercesor que en toda transformación y pugna se manifiesta como tensión. Se trata de la naturaleza desde un punto de vista unitario e invisible, pero también de cada una de sus disputas y dinamismos visibles, es decir, se trata del logos mismo que la gobierna" ${ }^{26}$. Volveremos sobre el tema del $\lambda$ ó $\gamma$ os en el apartado siguiente. Es importante resaltar aquí la idea de mirar desde el punto de vista invisible y desde el punto de vista visible, puesto que aquí se ve claramente el resultado de pensar el fuego, lo divino y el lógos como algo unitario, pues lo que resulta de ello es entender la unicidad del fundamento

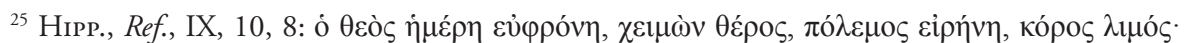

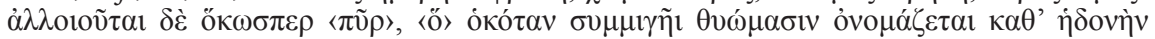

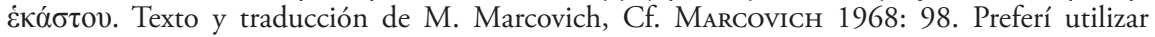
la traducción de Marcovich especialmente porque elimina la glosa explicativa de Hipólito entremedio del texto, que Mondolfo mantiene y no distingue del resto del fragmento de manera explicita. Cf. también el comentario de KIRK 1962²:184-188. La traducción de Kirk es como sigue: "God is day night, winter summer, war peace, satiety hunger -all the opossites, this is the meaning - and undergoes alteration in the way that fire, when it is mixed with spices, is named according in the scent of each of them". Donde las cursivas son una "explanatory gloss" de Hipólito. Puede verse también la revisión de las tres alternativas propuestas para la laguna del texto en R. Mondolfo 2007: 205-211.

${ }^{26}$ G. FERNÁNDEZ 2011: 100 
de todo según Heráclito y que ese mismo fundamento es tanto trascendente como

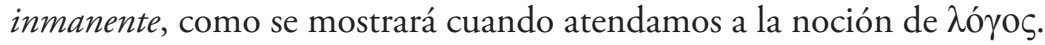

Ahora bien, si nos preguntamos qué carácter ontológico, qué dignidad posee el $\theta \varepsilon$ ć $\varsigma$ aquí conjuntado con los opuestos, se nos aparece el Fr. B 114, donde Heráclito dice taxativamente que todas las leyes humanas provienen, se alimentan, de una única ley divina y que quien comprenda esto está fortaleciéndose con lo común de las cosas, además de actuar con inteligencia, es decir, ser sabio. El fragmento reza: "Los que hablan con inteligencia es menester que se fortalezcan con lo que es común a todos, asi como una ciudad con la ley, y mucho más fuertemente. Pues todas las leyes humanas son alimentadas por la única ley divina; ésta, en efecto, impera tanto cuanto quiere, $y$ basta a todas las cosas y las trasciende" ${ }^{27}$. Lo que hace Heráclito aquí es decir que hay una ley divina que es superior a toda ley humana y que la gobierna de manera absoluta; ninguna institución humana, en el sentido de instituir, puede escaparse a ella, que gobierna cuanto quiere, abarcándolo todo y aun sobrando en cuanto a su superioridad.

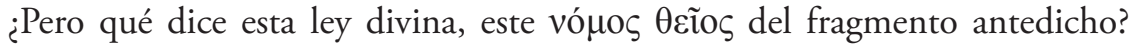
¿Cual es el contenido de la ley divina, lo que en definitiva hace o posibilita el movimiento ordenado del fuego divino? $\mathrm{O}$ mejor dicho, ¿qué tiene que ser esta ley divina para que todo acontezca como acontece según Heráclito? La ley divina da claras luces de ser lo mismo que el $\lambda$ ó yos. Vamos por ello.

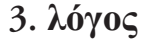

Aquí el camino comienza a ponerse pedregoso. Partamos primero de la discusión en torno al sentido de la palabra $\lambda o ́ \gamma o \varsigma$ en el Fr. B $1^{28}$ de Heráclito, leemos primero el griego y luego la traducción que adoptamos:

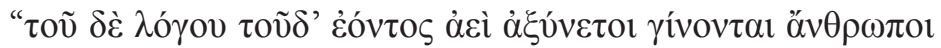

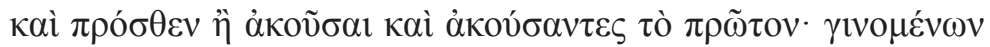

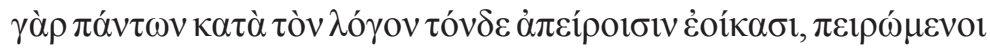

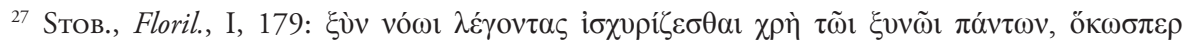

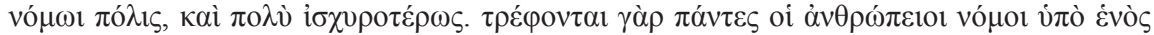

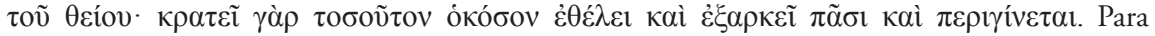
$\pi \varepsilon \rho \imath \gamma i ́ \gamma v o \mu \alpha$, quizá una traducción más ajustada al sentido de la palabra sea 'es mejor', 'es superior', 'supera', etcétera, pensando que 'las trasciende' está cargada de sentido metafísico que es poco probable que lo tuviera en tiempos de Heráclito. Puede verse una traducción más moderada en Marcovich 1968: 40: "...basta a todas (las leyes humanas), y aun sobra."

${ }^{28}$ SeXt. Emp., Adv. Math., VII, 132.
} 


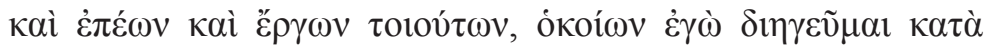

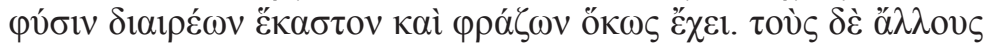

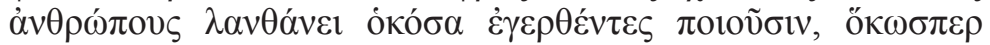

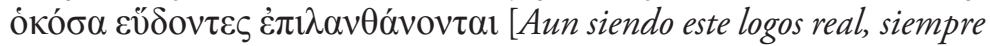
se muestran los hombres incapaces de comprenderlo, antes de haberlo oido y después de haberlo oido por primera vez. Pues a pesar de que todo sucede conforme a este logos, ellos se asemejan a carentes de experiencia, al experimentar palabras y acciones como las que yo expongo, distinguiendo cada cosa de acuerdo con su naturaleza y explicando como está. En cambio, a los demás hombres se les escapa cuanto hacen despiertos, al igual que olvidan cuanto hacen dormidos]"29.

Esto es el grueso de lo que el $\lambda$ ó $\gamma$ o significa en Heráclito. Pero hay aquí una ambigüedad, porque los editores modernos han discutido el sentido preciso de esta palabra hasta el cansancio. Lo que ha quedado bastante claro en la discusión es que hay al menos dos sentidos de $\lambda$ ó ${ }^{\circ}$ s en B 1, el de "discurso", por un lado, y con ello se "aterriza" un poco el asunto y este $\lambda$ ó $\gamma o \zeta$ se estaría refiriendo nada más que a las propias palabras de Heráclito, lo que no deja se ser problemático, en la medida en que este sentido choca con el segundo sentido que ven los eruditos en este término, el de una suerte de "ley universal" o "ley del devenir", obedeciendo

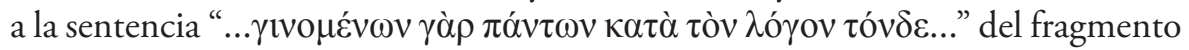
en cuestión, pues se pone de relieve algo más que la mera cualidad de discurso al $\lambda$ ó ${ }^{\circ} \varsigma$, tesis que encontraría apoyo en el afamado B 50, donde Heráclito hace

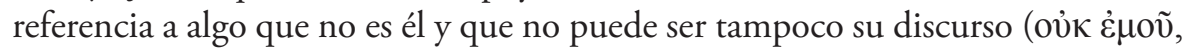

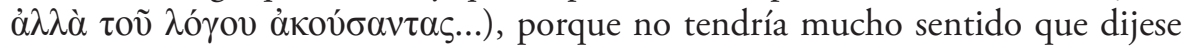

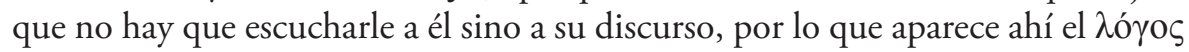
como algo externo, cuyo contenido haría pensar en que "todo es uno". De ahí que muchos de los editores no traduzcan la palabra ${ }^{30}$.

${ }^{29}$ La traducción es de R. Mondolfo. Marcovich traduce en la misma línea: "Of this Truth, real as it is, men always..." Cursivas mías. Pero por ejemplo A. García Calvo 2006³, traduce: "Esta razón, siendo ésta siempre como es, pasan los hombres...”, o J. E. Rivera 2006: "De este logos que es siempre llegan a ser incomprensores....", G. S. KIRK $1962^{2}: 33$, por su parte: "Of the Logos which is as I describe it men always...”.

${ }^{30}$ Por ejemplo G. S. Kirk 1962²: 33, R. Mondolfo 2007: 30, J. E. Rivera 2006, Kirk-RavenSchofield 1987, S. N. Mouraviev 2006: 2. Nuestra opción de traducción es la misma, no traducir $\lambda$ ó $\gamma$ os, considerando principalmente la polisemia que este término tiene en el discurso de Heráclito. Puede verse, a parte del análisis de los 11 sentidos que tiene $\lambda$ ó ${ }_{0} \varsigma$ en época arcaica de W. K. C. Guthrie 1984: 395-400, el texto de E. Hülzs 2001: 73 ss, donde analiza los 9 sentidos que encuentra él en este vocablo en Heráclito. En la línea de quienes se aventuran a traducir sobran las interpretaciones, por ejemplo, Marcovich traduce según el significado de los fragmentos, como en B 1, donde vierte $\lambda$ ó ${ }^{\circ} \varsigma$ por "Truth", en B 39 (M 100) por "account" y en B 45 (M 67) por "measure", y así otros como G. Colli (espressione), A. Capizzi (testo), A. G. Calvo (razón). 
Además de esta dificultad, existe otro problema tradicional al abordar este fragmento y es el de puntuarlo o no, para salvar la equivocidad que presenta la forma ỏeí ahí donde está en B 1, pues, como es sabido desde Aristóteles, es

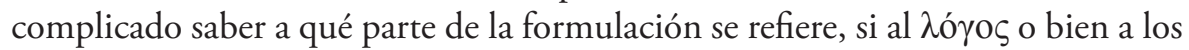
$\ddot{\alpha} v \theta \rho \omega \pi \mathrm{o}$, lo que resultaría en interpretaciones muy diversas del pensamiento de Heráclito. En la traducción que hemos adoptado, Mondolfo elige cargar el adverbio a los $\alpha$ $v \theta \rho \omega \pi \mathrm{ol}$, quedando la frase: "siempre se muestran los hombres incapaces...", lo que en cierto sentido es verdad, pero no puede serlo de manera absoluta, sobre la base de las características del discurso y de las posibles intenciones de Heráclito tanto al escribirlo y depositarlo en el Artemision como al declamar su enseñanza oralmente, puesto que la negación así de absoluta de comprensión a los hombres choca no sólo con la lógica de la comunicabilidad del discurso, sino con la propia inteligencia del texto (que va dirigida especialmente a los hombres) no menos que con algunos de los propios fragmentos de Heráclito ${ }^{31}$, como son el Fr. B 116: "a todos los hombres les está concedido conocesre a sí mismos y ser sabios" ${ }^{2}$, y también el Fr. B 113, entre otros 33: "común es a todos la inteligencia"34, donde es evidente que Heráclito no pensó que el hombre fuese incapaz siempre de comprender.

Sumado a este problema, existe otro escollo a que atenerse para analizar el proemio del libro de Heráclito, y es el pronombre $\tau 0 \tilde{v} \delta$ ' que aparece entre $\lambda o ́ \gamma o v$

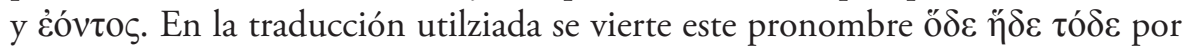
"real", lo que no deja de tener sentido si pensamos que en el diccionario de Liddel \& Scott, significa "más claramente lo que está presente, lo que puede ser visto o señalado", con lo cual "real" tiene sentido pleno. Pero el problema se suma al de la posición del ácí, puesto que si decimos que el "lógos es real”, no decimos lo mismo si lo reforzamos diciendo que es real "siempre". Pero como hemos adoptado la posición del àcí más hacia el lado del lógos, tenemos que decir que el $\lambda$ ó $\gamma$ os es real y que lo es siempre ${ }^{35}$.

Ahora bien, concentremos la antención en lo siguiente. El fragmento nos dice que todo $(\pi \alpha ́ v \tau \alpha)$ nace, sucede, viene a ser, acontece, según o en función de este

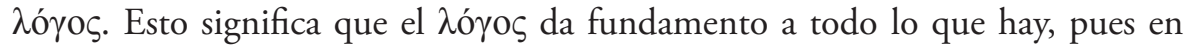

\footnotetext{
${ }^{31}$ Puede verse al respecto el análisis de M. García Quintela 1992: c. III.

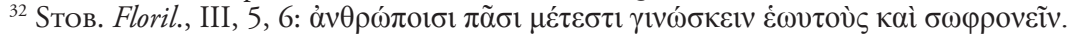

${ }^{33}$ Como B 34, B 112, B 17, B 87, B 55, B 19.

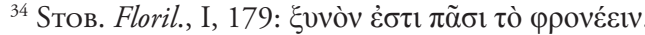

${ }^{35}$ Ver la propuesta de A. García Calvo 2006³: 32-33.
} 
ordenación a él es que hay lo que hay. Por ello que en el Fr. B 2: "Por eso conviene seguir lo que es general a todos, es decir, lo común; pues lo que es general a todos es común. Pero aun siendo el logos general a todos, los más viven como si tuvieran una inteligencia propia particular" 36 , Heráclito dice que el $\lambda o ́ \gamma o \varsigma$ es común a todos, es decir, un algo que pertenece a todo hombre a la vez que lo abraza. Esto no puede apuntar a otro sitio que a la ley divina con la que, volviendo al Fr. B 114, dice Heráclito deben fortalecerse los que hablan con inteligencia, los sabios, es

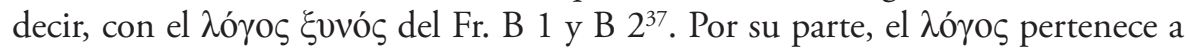
todo hombre, no sólo porque éste está incluido en el mundo que el lógos regula, ordena, ya que no se trata de la simple inclusión en el orden del mundo, como simple parte en un todo. Lo que hace que el $\lambda o ́ \gamma o \varsigma$ pertenezca de alguna manera al hombre, no es la mera participación, sino la total y absoluta unión que establece Heráclito, y hasta subordinación podríamos decir, entre el hombre y la ley divina o $\lambda o ́ \gamma o s$, puesto que en el Fr. B 45: "Los limites del alma, por más que procedas, no lograrás encontrarlos aun cuando recorrieras todos los caminos: tan hondo tiene su logos" 38 , Heráclito nos pone al descubierto que nuestra alma posee un hondo $\lambda o ́ \gamma o \varsigma$, esto es, que su esencia es tener un $\lambda$ ó $\gamma$ os que es difícil de encontrar, por más que nos esforcemos. Pero esto no es un mero decir, y he aquí la clave del asunto, donde la filosofía heraclítea toma un carácter unitario tremendamente profundo. Hemos hablado de $\lambda$ óyos en el sentido de principio o norma del mundo, ley del devenir, y es justamente en este sentido que tiene que entenderse la así llamada "doctrina del $\lambda o ́ \gamma o \varsigma$ " en Heráclito, para dar fuerza a su discurso, a su propio $\lambda$ ó $\gamma o \varsigma$, y entender que lo que está pensando, o lo que nos invita a pensar su filosofía como una filosofía total, si se nos permite el término, en la que se abarca toda esfera humana y se unifica en una nueva visión de la realidad.

Si se observa, hemos alcanzado lo suficiente para llegar a plantear la inmanencia y trascendencia unísona del $\lambda o ́ \gamma o s$ que, como ya ha quedado de manifiesto, puede entenderse de igual modo que el $\pi \tilde{u} \rho$ y el $\theta \varepsilon o ́ s$. Esta aparente paradoja inmanente-trascendente no es sino la culminación de la sabiduría heraclítea, su

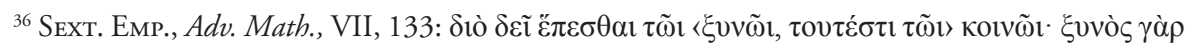

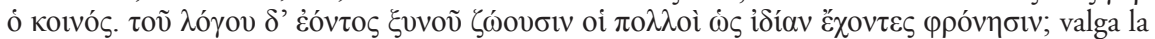

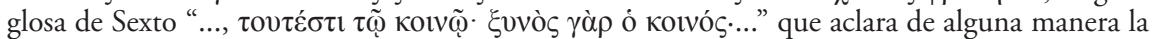

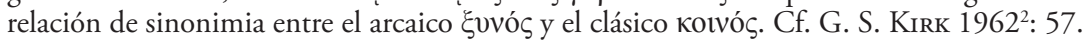

${ }^{37}$ Cf. R. Mondolfo 2007: 155-165; W. Jaeger 1952: 111-128; G. S. Kirk 1962²: 33-71. S. Aguilera 2013: 27 ss.

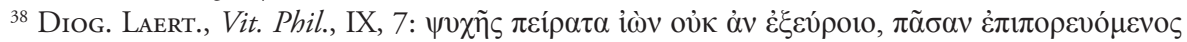

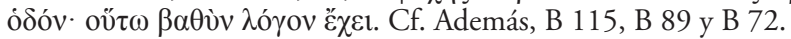


punto más alto y su verdad más honda, la unidad total de todas las $\operatorname{cosas}^{39}$. Que acaba en el famoso Fr. B 50: "no escuchando a mí, sino al lógos, sabio es que reconozcas que todas las cosas son Uno" 40 , donde Heráclito reafirma este saber total.

\section{Consideraciones finales}

Este saber totalse presenta precisamente en el contenido del saber al que llega el hombre según Heráclito, es decir, el contenido del lógos: todo es uno, una unidad comprehensiva de todo, a nivel tanto epistemológico como ontológico. Este lógos, que es a la vez un contenido accesible al hombre mediante su inteligencia y una norma del devenir, pues regula todo acontecer con su ser: el devenir de los contrarios, es tanto trascendente como inmanente. Trascendente en la medida en que Heráclito ha dicho en el Fr. B 108 que lo sabio está $\pi \alpha ́ v \tau \omega \nu \kappa \varepsilon \chi \omega \rho \iota \sigma \mu \varepsilon ́ v o v$ y en el Fr. 114 que la ley divina alcanza para todo y aun sobra o sobrepasa, $\pi \varepsilon \rho 1 \gamma i ́ v \varepsilon \tau \alpha$. Inmanente en la medida en que la propia alma del hombre tiene un $\beta \alpha \theta i ̀ \varsigma \lambda o ́ \gamma o \varsigma$, pero también en la medida en que el lógos esta ahí, frente a nuestras narices, en aquello de lo que podemos tener alguna experiencia, en aquello de lo que podemos tener alguna comprensión, es decir, en nosotros mismos y en el mundo que nos rodea. Aunque, sin bien es cierto que esto es así, hablar de trascendecia e inmanencia en el pensamiento de Heráclito resulta anacrónico, y sólo pueden utilizarce legítimamente estos términos para explicar la realidad a la que Heráclito está haciendo referencia, nada más que para eso, pues para abarcar de la misma forma, o al menos de una manera semejante, lo que quizo decir el efesio, debemos trascender las determinaciones dualistas, como resulta también la dualidad trascendente-inmanente. Por ello Heráclito, además de proponer un saber tal, nos invita más que a aprender un mero saber, a trascender todo saber y a trascender nuestras experiencias habituales en buscas de aquella unidad a la que indica el lógos dentro de su filosofía.

Para finalizar, y no extender la discusión más de lo necesario, una cita de Jaeger, quien simplemente ha intuido profundamente un sentido valiosísimo en

${ }^{39}$ Cf. G. Fernández 2011: 99: "Cuando Heráclito habló de «la divinidad» como instancia donde coinciden y se resuelven las oposiciones (cfr. 22 B 67 DK), parece evidente que estaba pensando en el lógos, contraponiendo el calado de este conocimiento, la "sabiduría», con el limitado conocimiento que tienen los hombres de esta norma cósmica que da lugar a la coincidentia oppositorum. Lo que Heráclito quiere decir es que, en contra de nuestra propia experiencia, que distingue una cosa de otra, que enfrenta una cosa con otra, el sabio es capaz de ver que, lo que se presenta de modos tan diversos, oculta en su fondo una identidad en la oposición". Cf. Además, W. JAeger 1962²: 177 ss, 1952: 118 ss; W. Guthrie 1984: 444.

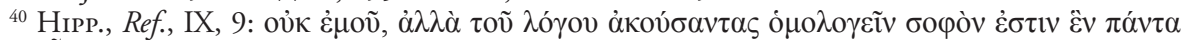
Eĩvol. Las negritas son mías. 
las palabras de Heráclito y que resume, en alguna medida, lo que hemos querido mostrar aquí:

"Heráclito funda el dominio de la sabiduría cósmica, superior a la inteligencia ordinaria de los hombres, en su original doctrina de los contrarios ${ }^{41}$ y de la unidad del todo ${ }^{42}$. También esta doctrina de los contrarios se halla en parte íntimamente relacionada con las representaciones físicas concretas de la filosofía natural milesia. Pero su fuerza vital no procede de las sugestiones de otros pensadores, sino de la intuición inmediata del proceso de la vida humana que se concibe como una biología que abarca, en una unidad compleja y peculiar, lo espiritual y lo físico como hemisferios de un solo ser” ${ }^{\text {”3 }}$.

\begin{tabular}{|c|c|c|c|}
\hline \multicolumn{4}{|c|}{ Abreviaturas de Fuentes Utilizadas } \\
\hline $\begin{array}{l}\text { Clem. = Clemente } \\
\text { Stromat. } \\
\text { Diog. Laert. = } \\
\text { Diógenes Laercio } \\
\text { Vit. Phil. } \\
\text { Hipp. = Hyppolitus } \\
\text { Ref. } \\
\text { Orig. = Origenes } \\
\text { C. Cels. }\end{array}$ & $\begin{array}{l}\text { Stromateis } \\
\text { (Misceláneas) } \\
\\
\text { Vitae Philosophorum } \\
\text { (Vida de los } \\
\text { filósofos) } \\
\text { Refutatio omnium } \\
\text { haeresium } \\
\text { (Refutación a todas } \\
\text { las herejías) } \\
\\
\text { Contra Celsum } \\
\text { (Contra Celso) }\end{array}$ & $\begin{array}{l}\text { Plat. = Platón } \\
\text { Hipp. maior } \\
\text { Plut. = Plutarco } \\
\text { De E. } \\
\text { De exil. } \\
\text { Porphyr. = Porfirio } \\
\text { Quaest. Hom. } \\
\text { Sext. Emp. = } \\
\text { Sexto Empírico } \\
\text { Adv. Math. } \\
\text { Stob. = Estobeo } \\
\text { Floril. }\end{array}$ & $\begin{array}{l}\text { Quaestiones } \\
\text { Homericae } \\
\text { (Cuestiones } \\
\text { Homéricas) } \\
\\
\text { Adversus } \\
\text { Mathematicos } \\
\text { (Contra los } \\
\text { matemáticos) } \\
\text { Florilegium } \\
\text { (Antología) }\end{array}$ \\
\hline
\end{tabular}

${ }^{41}$ Es original en el sentido propio que tiene en Heráclito, puesto que es sabido que el lenguaje de oposiciones es una forma estilística propia de su tiempo, Cf. H. FränKEL 2004²: 349, n. 2.

${ }^{42} \mathrm{Si}$ bien es cierto esta idea general ya aparece en la época de Heráclito, donde se concibe como unitario cosmos y hombre, el peso y originalidad de Heráclito en este tema radica especialmente en comprender al hombre mismo como parte activa y con responsabilidad sobre sí mismo en el decurso o devenir del propio mundo. Cf. especialmente W. JAEger 1962²: 178, 180. 


\section{Referencias bibliográficas}

Aguilera, S., (2013) "La Política del Lógos: Reflexiones sobre el pensamiento político de Heráclito de Éfeso”, en Byzantion Nea Hellás, 32, pp. 13-35.

Barruecos, B., (2012) "Quaestiones Heracliteae. Análisis y comentario de los Nuevos ensayos sobre Heráclito”, Diánoia, vol. LVII, n 69, pp. 185-209.

Benveniste, Émile (1983) Vocabulario de las instituciones indoeuropeas, Madrid: Taurus.

Bernabé, Alberto (2009) "Expresiones polares en Heráclito", en Hülsz Piccone, E., (ed.), Nuevos ensayos sobre Heráclito, México, pp. 103-137.

Caballero, Raúl (2008) "Las musas jonias aprenden a escribir: ley escrita y tratado en prosa en los milesios y Heráclito", Emerita, vol. 76, n 1, pp. 1-33.

Capizzi, Antonio (1979) Eraclito e la sua leggenda. Proposta di una diversa lettura dei frammenti, Roma: Dell'ateneo \& Bizzarri.

Capelle, Wilhelm, (1981) Historia de la filosofía griega. Trad. de Emilio Lledó, Madrid: Gredos. 1 ed., W. de Gruyter, Berlín, 1954.

Cappelletti, Angel (1974) Diogenes de Apolonia y la segunda filosofía jónica, Maracaibo: Universidad del Zulia.

Chantraine, Pierre (1968) Dictionnaire ètymologique de la langue grecque. Histoire des mots. Paris: Klincksieck.

Colli, Giongio (2010) La sabiduría griega III: Heráclito, Madrid: Trotta.

Conche, Marcel (1986) Héraclite: Fragments. Paris: PUF.

Diels, Herman y Kranz, Walter (1974) Die Fragmente der Vorsokratiker, Berlín: Weidmann.

Fernández, Gustavo, (2011) "Lo divino como resolución de la oposición en el pensamiento de Heráclito”. En Fragmentos de filosofía, N 9, pp. 97-116.

Fränkel, Hermann, $\left(2004^{2}\right)$ Poesía y filosofía de la Grecia arcaica. Madrid: A. Machado Libros.

${ }^{43}$ W. Jaeger 1962²: 179-180; Cf. también W. Guthrie 1984: 444: "Para Heráclito, como hijo de su tiempo, no sería ilógico, sino natural pensar en el principio divino no sólo como inmanente, sino también como externo". Asimismo W. CAPELle 1981: 76-77, llega a caracterizar la teoría del lógos heraclíteo y su visión general del mundo como el "panteísmo más sublime" o como un "monismo panteísta". 
García Calvo, Agustín (2006³) Razón Común. Edición crítica, ordenación, traducción y comentario de los restos del libro de Heraclito, 1985', Zamora: Lucina.

García Quintela, Marco (1992) El rey melancólico. Antropología de los fragmentos de Heráclito. Madrid: Taurus.

Gigon, Olof, (1980) Orígenes de la filosofía griega, de Hesiodo a Parménides, Madrid: Gredos.

Guthrie, W. K. C., (1984) Historia de la Filosofía griega, Tomo I, Madrid: Gredos.

HüLsz, E., (2009) Nuevos ensayos sobre Heráclito. Actas del $2^{\circ}$ Symposium Heracliteum, México D. F: UNAM.

F: UNAM, (Tesis Doctoral)

, (2001) $\Lambda \mathrm{OГО \Sigma :} \mathrm{Heráclito} \mathrm{y} \mathrm{los} \mathrm{orígenes} \mathrm{de} \mathrm{la} \mathrm{filosofía,} \mathrm{México} \mathrm{D.}$

Jaeger, W., (1962²) Paideia, los ideales de la cultura griega. México D. F.: Fondo de Cultura Económica, $18^{\circ}$ reimp. 2006.

, (1952) La teología de los primeros filósofos griegos. México D. F.: Fondo de Cultura Económica, $1^{\circ}$ reimp. 2003.

, (1982) Alabanza de la ley: los orígenes de la filosofía del derecho y los griegos. Madrid: Centro de estudios Constitucionales.

Kahn, Charles, (1979) The art and thought of Heraclitus, London: Cambridge University Press.

Kirk, Geoffrey Stephen (1962²) Heraclitus, the cosmic fragments, Great Britain: Cambridge University Press.

Kirk, G. S., Raven, J. E. \& Schofield, M., (1987) Los filósofos presocráticos, $2^{\circ}$ ed., Madrid: Gredos (ed. inglesa, The presocratic Philosophers. Cambridge University Press, 1957)

Kostas, Axelos, (1962) Héraclite et la philosophie. Paris: Éditions de Minuit.

Kranz, Walther (1949) "Der Logos Heraklits und der Logos des Johannes", Rheinisches Museum für Philologie, Sauerländer Verlag, Neue Folge, 93 Bd. 1 H., pp. 81-95.

Laercio, Diógenes, (2007) Vidas de los filósofos más ilustres, Trad. Carlos García Gual, Madrid: Alianza.

Marcovich, Miroslav (2003) Heraclitus, greek text with a short commentary (Editio Maior). Academia Verlag, Sankt Agustin, $2^{\circ}$ ed. (Edición aumentada de la $1^{\circ} \mathrm{ed}$. MARCOVICH, M, Heraclitus, greek text with a short commentary. U. 
Andes, Mérida, Venezuela, 1967 y de la edición italiana, Eraclito. Frammenti. La Nuova Italia, Firenze, 1978)

Mérida: Talleres Gráficos Universitarios.

Mondolfo, Rodolfo (2007) Heráclito, textos y problemas de su interpretación, $13^{\circ}$ ed., México: S. XXI. , (1935) L'infinito nel pensiero dei greci. Firenze: Felice le Monnier. (Ed. cast. Aumentada, El infinito en el pensamiento de la antigüedad clásica. Buenos Aires: Imán, 1952.)

Mouraviev, Serge (2006) Heraclitea III.3.B/i. Les Fragments du Livre d'Héraclite. Les textes pertinents. Textes, traductions, apparats I-III, Academia Verlag: Sankt Agustin.

Nussbaum, Martha, (1972) "ЖYXH in Heraclitus", Phronesis, 17, pp. 1-16; 153-170.

Pòrtulas, Jaume, (1993) "Heráclito y los maîtres à penser de su tiempo", Emerita, vol. 61, n 1, pp. 159-176.

Rivera, J. E., (2006) Heráclito el esplendente. Santiago: Brickle Ediciones.

Sambursky, S., (2011) El mundo físico de los griegos. Trad. Ma. José Pascual Pueyo, Madrid: Alianza. 